\section{A NEW HOST RECORD AND A NEW COMBINATION in COTESIA CAMERON (HYMENOPTERA: BRACONIDAE) FROM INDIA}

\section{Ankita Gupta ${ }^{1}$ \& Swapnil A. Lokhande ${ }^{2}$}

${ }^{1}$ National Bureau of Agriculturally Important Insects, Post Bag No. 2491, H. A. Farm Post, Bellary Road, Hebbal, Bengaluru, Karnataka 560024, India 2 Department of Mathematics, IIT-Bombay, Powai, Mumbai, Maharashtra 400076, India

${ }^{1}$ drankitagupta7@gmail.com (corresponding author), ${ }^{2}$ swaplokhande@gmail.com

Genus Cotesia Cameron is the second largest genus of subfamily Microgastrinae (Hymenoptera: Braconidae) from the Indian region after Apanteles Förster. Cotesia is the commonest and the most ubiquitous genus, comprising nearly 1500-2000 species worldwide (Mason 1981). The species are mostly gregarious in nature with only a few solitary forms. They mainly parasitize caterpillars of Noctuidae, Geometridae and Saturniidae (Whitfield et al. 2009). Literature review shows that nearly 34 species are recorded from the Indian region (unpublished data of the first author) with a few cosmopolitan species. Some frequently encountered Indian species of the Genus Cotesia inhabiting various agro-ecosystems include Cotesia flavipes Cameron, gregarious parasitoid infesting graminaceous stem borers Chilo partellus (Swinhoe) and Chilo sacchariphagus (Bojer); Cotesia vestalis (Haliday), solitary parasitoid of the diamondback moth Plutella xylostella (L.); Cotesia glomerata (Linnaeus), potential parasitoid of Pieris brassicae (Linnaeus), Pieris rapae (Linnaeus), Spodoptera frugiperda (Smith), Bombyx mori (Linnaeus), Agrotis ipsilon (Hufnagel), Lymantria dispar (Linnaeus) and Trichoplusia ni (Hübner); Cotesia kazak
(Telenga), solitarylarval parasitoid of Helicoverpa armigera (Hübner) and Helicoverpa zea (Boddie); Cotesia marginiventris (Cresson) infesting Helicoverpa armigera (Hübner) and Spodoptera litura (Fabricius); Cotesia ruficrus (Haliday) infesting

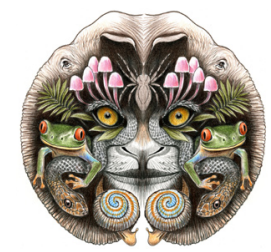

ISSN

Online 0974-7907 Print 0974-7893

\section{OPEN ACCESS} Pelopidas mathias (Fabricius) on rice, $P$. brassicae (Linnaeus) and $P$. rapae (Linnaeus) on cabbage, Pectinophora gossypiella (Saunders) on cotton, Plutella xylostella (Linnaeus) on cabbage, Helicoverpa armigera (Hubner) on many crops, Spodoptera spp. and Chilo sp.; Cotesia chilonis (Munakata) infesting Chilo partellus (Swinhoe), Chilo infuscatellus Snellen and Chilo suppressalis Walker; Cotesia sesamiae (Cameron) as larval parasitoid of Chilo partellus (Swinhoe) and Cotesia melanoscela as parasitoid associated with Lymantria dispar Linnaeus.

In the present study, a new combination is proposed for Cotesia tiracolae (=Apanteles tiracolae), which is recorded as a larval parasitoid of Phaedyma columella (Cramer) (Lepidoptera: Nymphalidae) feeding on the host plant Grewia tiliifolia Vahl from Mumbai, Maharashtra, India. This is the first record of larval parasitism associated with P. columella from India. Cotesia tiracolae comb. nov. is redescribed and illustrated.

Materials and Methods: The wasps were bred from the parasitized caterpillar collected from Indian Institute of Technology, Mumbai campus. Specimens were preserved in $70 \%$ alcohol. Alcohol preserved specimens were critically point dried and later card mounted and identified consulting Wilkinson (1928) and Mason (1981). The parasitoid images were taken using a Leica M 205 A stereozoom microscope with Leica DC

\footnotetext{
DOI: http://dx.doi.org/10.11609/JoTT.03283.3678-81 | ZooBank: urn:Isid:zoobank.org:pub:3887C8DD-6E23-461F-8745-21557B9C1BF3
}

Copyright: (c) Gupta \& Lokhande 2013. Creative Commons Attribution 3.0 Unported License. JoTT allows unrestricted use of this article in any medium, reproduction and distribution by providing adequate credit to the authors and the source of publication.

Funding: Taxonomic studies were undertaken by the first author with the funds from the Indian Council of Agricultural Research, New Delhi. Field studies/data was contributed by the second author.

Competing Interest: None.

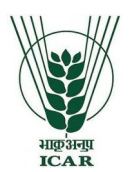

Acknowledgements: We are grateful to the Indian Council of Agricultural Research and Dr. N.K. Krishna Kumar, Director, NBAll, Bangalore, for providing necessary facilities for carrying out this research work. Our special thanks to Keith Wolfe, Expert on butterfly caterpillars and their host plant utilization, California and Milind Bhakare, Butterfly Expert, India for the prompt identification of the host caterpillar. Many thanks to Peter Smetacek, Lepidoptera Expert, India for sharing his expertise and time. Second author is thankful to Abhay Soman for giving field support and mentoring. We are indeed indebted to dedicated researchers Blaise Pereira and Paresh Kale for their constant support and valuable inputs. 
420 inbuilt camera using automontage software (version 3.8). Images of the host were captured using Canon Powershot SX30 IS.

\section{Results}

\section{Cotesia tiracolae (Ashmead), new combination (Images 1-11)}

Apanteles tivacholae, Ashmead 1896. Proc. U. St. Nat. Mus., xviii, no. 1092, p. 647, female, male.

Apanteles tiracholae. Wilkinson 1928, Bull. Ent. Res., xix, p. 102.

Apanteles tiracolae Ashmead 1896. Yu (2012).

Cotesia tiracolae (Ashmead) comb. nov., Howard \& Ashmead, 1896 is reassigned from the traditionally defined Apanteles based on the presence of the following characters:

Material examined: NBAll/Bra/Mic/Cot/tira/29612, 29.vi.2012, six females mounted on card, Powai, Maharashtra, India, bred from parasitized larvae of Phaedyma columella (Cramer) (Lepidoptera: Nymphalidae) on host plant Grewia tiliifolia Vahl, coll. Swapnil A. Lokhande. All specimens deposited in the National Bureau of Agriculturally Important Insects (NBAII), Bengaluru, India.

Diagnosis: Female (Image 3). Body length $2.5 \mathrm{~mm}$. Black. Antennae mostly black, scape yellow brown with apex black; tegulae brown; fore and mid legs testaceous red (except red brown coxae with slight bluish-black tinge dorsally). Hind coxa black with white apex, rugose punctate and shining. Hind femora tipped with black; hind tibia darkened towards apex and hind tarsi dark brown. Hind tibial spurs subequal and pale testaceous; individually shorter than half of basitarsus. Forewings with pterostigma and wing veins brown; R1 vein longer than stigma. Hindwings with margin of vannal lobe almost convex and hairy throughout (Image 4).

Head (Image 5) and mesosoma (Image 7) densely punctate, punctations denser in head. Mesoscutum evenly and strongly punctate; scutellum shining, shallowly and sparsely punctate. Propodeum (Image 8 ) rugose, without areola, with a more or less complete median longitudinal carina from which emerge oblique carinae, and with strong basal transverse carinae.

Metasoma laterally testaceous yellow-red except last and second last lateral tergites black; $1^{\text {st }}$ and $2^{\text {nd }}$ tergite with lateral margins pale testaceous, $3^{\text {rd }}$ tergite testaceous red laterally, paler on latero-apical margin, suffused with black in the middle; basal ventrites testaceous yellow. Pale lateral margins of $1^{\text {st }}$ and $2^{\text {nd }}$ tergite narrower than lateral margins of $3^{\text {rd }}$ tergum. Tergum $1^{\text {st }}$ (Image 8 ) nearly

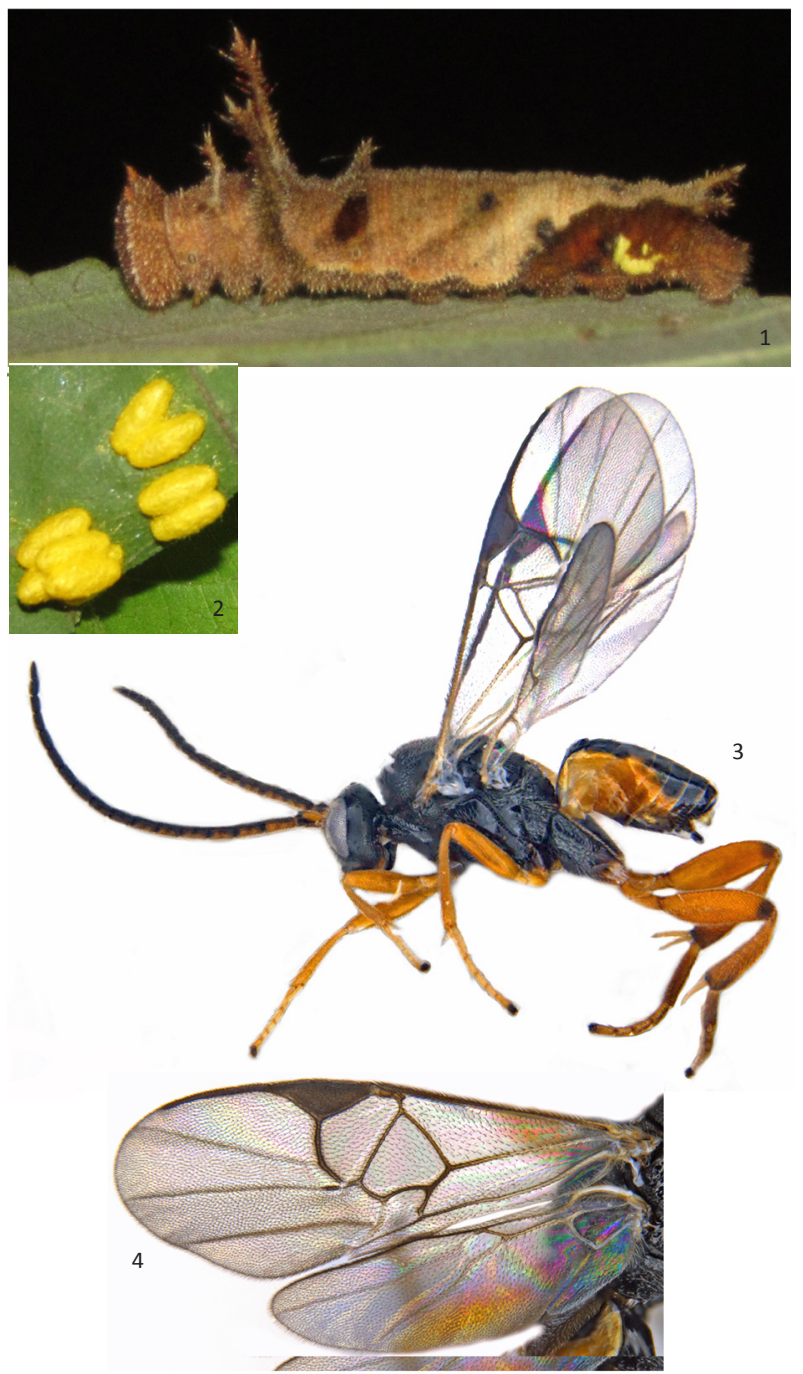

Images 1-4. 1 - Parasitised caterpillar of Phaedyma columella (Cramer); 2 - Cocoons of Cotesia tiracolae (Ashmead); 3 - Female wasp of Cotesia tiracolae (Ashmead), habitus view; 4 - Forewings and hindwings of $\boldsymbol{C}$. tiracolae female. (C) 1,2 - Swapnil A. Lokhande; 3,4 Ankita Gupta

quadrate, hardly longer than wide, its lateral margins subparallel with corners rounded; apical half coarsely but sparsely sculptured. Tergum $2^{\text {nd }}$ indefinitely sculptured with lateral sulci, basal margin little wider than apical margin of tergum $1^{\text {st }}$, tergum $2^{\text {nd }}$ shorter in median length than $3^{\text {rd }}$ but longer than $4^{\text {th }}$, subrectangular and indefinitely sculptured. Tergum $3^{\text {rd }}$ subrectangular and smooth. $4^{\text {th }}$ and $5^{\text {th }}$ tergites testaceous yellow mediolaterally with posterior margin black. Hypopygium short; ovipositor sheath shorter than half length of hind tibia, concealed by hypopygium, with a few hair concentrated at apex.

Types: Wilkinson (1928) redescribed this species from a cotype given by Dr. A.B. Gahan to the British Museum and from five females and one male, 10.i.1919, ex. larvae 

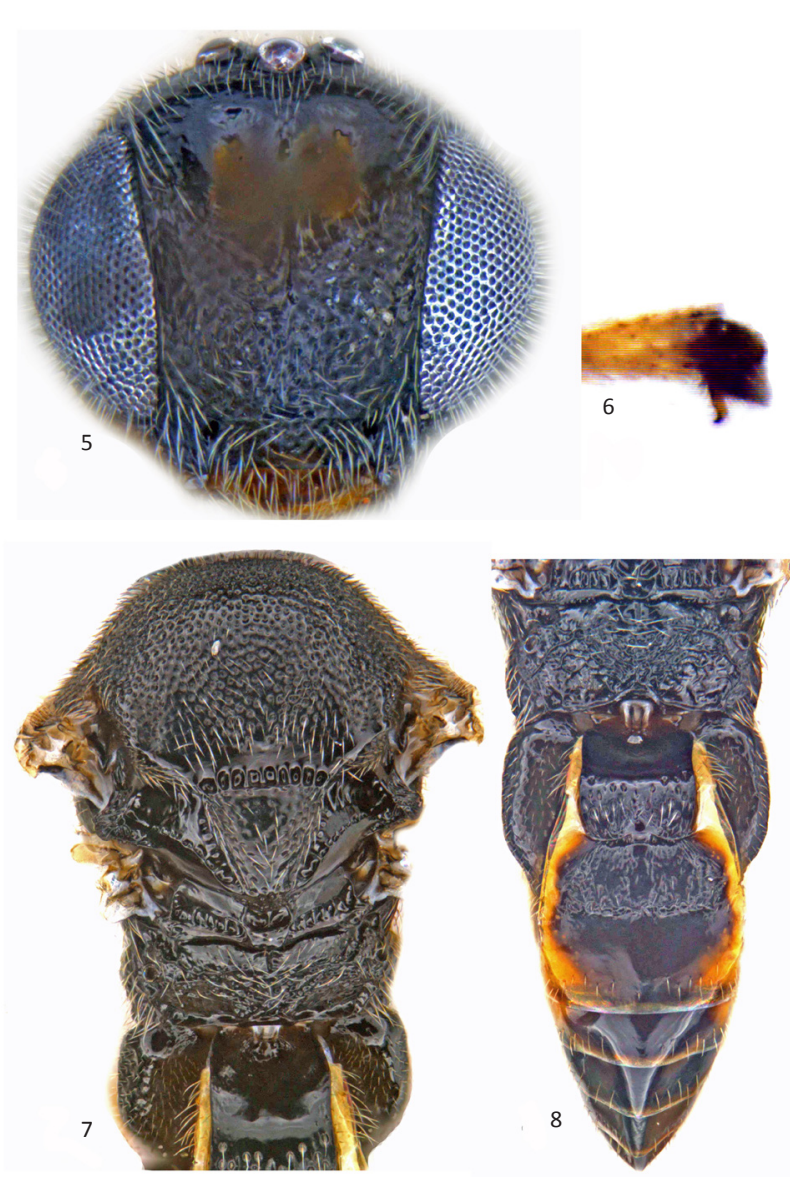

Images 5-8. Frontal view of head, $C$. tiracolae female; 6 - Fore tarsus, $C$. tiracolae female; 7 - Mesosoma with part of first metasomal tergite, $C$. tiracolae female; 8 - Propodeum \& metasoma, C. tiracolae female. (C) Ankita Gupta

of Tirachola plagiata Walker, type locality Ceylon.

Remarks: Both the genera, Apanteles Förster and Cotesia Cameron, are described in detail by Mason (1981). Genus Cotesia can be identified with following key characters: Propodeum mostly rugose, usually with a median carina and a short transverse carina running mesad from near the spiracle, never with an areolet, short inflexible hypopygium, short ovipositor. Tergum $1^{\text {st }}$ parallel sided or broadened posteriorly, mostly rugose. $2^{\text {nd }}$ tergum rectangular, rugose. The key characters of the Genus Apanteles include: Propodeum never showing trace of a median longitudinal carina but instead more or less well defined areola and costulae; ovipositor sheath usually long and hairy throughout. Hindwing with vannal lobe margin typically concave and hairless on the posterior part, in extreme case convex, though curve is somewhat flattened and sparsely hairy.

The original description of 'tivacholae' given by Ashmead (1896) lacks characters of propodeum which are very important in correct placement of species in the genus. The species description was based on 36 females and 14 males bred from larvae of Tirachola plagiata Walker. It mentions "two basal joints of antennae brownish-yellow. The legs are brownish-yellow, but all coxae black, while the apex of hind femora, apex of their tibiae and their tarsi are fuscuous, the scutellum is smoother; the abdomen is as long as the thorax and except ventor, the membranous margins of first and second segments and lateral dorsal spots on third and fourth segments, which are yellow and sometimes confluent, is black; the plate of first segment is long trapezoidal, more than twice as long as wide at apex and shagreened apically; the second is as long as the fourth, feebly shagreened; the third is very short".

The diagnostic characters of this species agree with the redescription of 'tiracholae' given in Wilkinson (1928). In the key to Indo-Australian species of Genus Apanteles provided by Wilkinson (1928) the species is placed in couplet $45^{\text {th }}$. The description includes
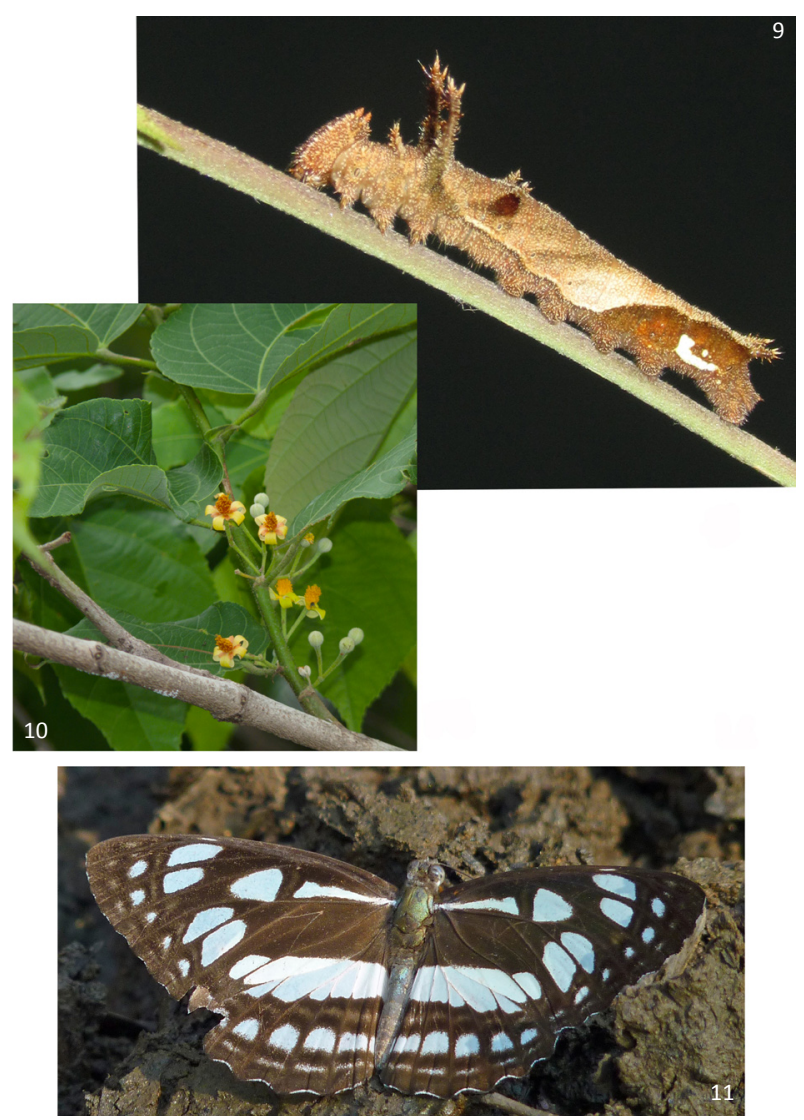

Images 9-11. 9 - Caterpillar of Phaedyma columella (Cramer); 10 - Host plant Grewia tiliifolia Vahl; 11 - Adult of Phaedyma columella (Cramer). (C) 9 - Swapnil A. Lokhande \& 10,11 - Abhay Soman 
propodeum characters stating "propodeon rugose with median longitudinal carina from which emerge oblique carinae and with strong basal transverse carinae".

Considering the following contradicting characters: Propodeum with strong rugosity and distinct median longitudinal carina, areola absent; shape and sculpture of $1^{\text {st }}$ and $2^{\text {nd }}$ tergite (similar to that of Genus Cotesia), the species is proposed to be rightly placed in Genus Cotesia instead of Apanteles.

Distribution: India (New distribution record) and Sri Lanka.

Host record: Phaedyma columella larva (Lepidoptera: Nymphalidae) on host plant Grewia tiliifolia Vahl. Also recorded from Agrotera basinotata Hampson (Lepidoptera: Crambidae), defoliator of Lagerstroemia parviflora from Central India, ICFRE (2009) and Tiracola plagiata (Walker) (Lepidoptera: Noctuidae) from Sri Lanka, Yu (2012).

\section{Discussion}

Both species, Cotesia tiracolae (Ashmead) and Protapanteles neptisis (Watanabe) attack same host Genus Neptis. P. neptisis is recorded as a larval parasitoid of Neptis coenobita Goeze (Lepidoptera: Nymphalidae) (Yu 2012). Morphologically, the genus Protapanteles is very close to the genus Cotesia (Whitfield 1997). Hence, both species are compared here as $C$. tiracolae can be confused in identification with $P$. neptisis. It differs in the following characters of $P$. neptisis - head, disc of scutellum and hind coxae smooth; cocoons white; first tergite $1.5 x$ longer than wide.

\section{Conclusion}

Cotesia tiracolae (Ashmead 1896), new combination, is redescribed and illustrated from India. Phaedyma columella larva parasitised by $C$. tiracolae confirms that this parasitoid is capable of infecting Nymphalidae in addition to the known host spectrum belonging to Crambidae and Noctuidae.

\section{REFERENCES}

Howard, L.O. \& W.H. Ashmead (1896). On some reared parasitic Hymenopterous insects from Ceylon. Proceedings of the United States National Museum 18: 633-648.

ICFRE (2009). Annual Report 2009-10. <http://www.icfre.org/ UserFiles/File/Annual-Report-2009-10-English-19Apr12/ForestProtection.pdf>. Downloaded on 31 July 2012.

Mason, W.R.M. (1981). The polyphyletic nature of Apanteles Förster (Hymenoptera: Braconidae): a phylogeny and reclassification of Microgastrinae. Memoirs of the Entomological Society of Canada 115: 1-147.

Whitfield, J.B. (1997). Subfamily Microgastrinae, pp. 333-364. In: Wharton, R., P.M. Marsh \& M.J. Sharkey (eds.). Manual of the New World genera of the family Braconidae (Hymenoptera). Special Publication No. 1, International Society of Hymenopterists, Washington, D.C

Whitfield, J.B., J.J. Rodriguez \& P.K. Masonick (2009). Reared microgastrine wasps (Hymenoptera: Braconidae) from Yanayacu Biological Station and environs (Napo Province, Ecuador): diversity and host specialization. Journal of Insect Science 9: 1-22.

Wilkinson, D.S. (1928). A revision of the Indo-Australian species of the genus Apanteles (Hymenoptera: Braconidae)-Part I. Bulletin of Entomological Research 19: 109-146.

Yu, D. (2012). Home of Ichneumonoidea. <http://www.taxapad.com>. Downloaded on 31 July 2012 